\title{
X-ray Photoelectron Spectroscopic Characterization of Au Collected with Atom Trapping on Silica for...
}

Article in Applied Spectroscopy · October 1997

DOI: 10.1366/0003702971939064

CITATIONS

31

4 authors, including:

\section{Sefik Suzer}

Bilkent University

176 PUBLICATIONS 2,500 CITATIONS

SEE PROFILE
READS

34

Osman Yavuz Ataman

Middle East Technical University

88 PUBLICATIONS 1,395 CITATIONS

SEE PROFILE

Some of the authors of this publication are also working on these related projects: 


\title{
X-ray Photoelectron Spectroscopic Characterization of Au Collected with Atom Trapping on Silica for Atomic Absorption Spectrometry
}

\author{
Ş. SÜZER, * N. ERTAŞ, S. KUMSER, and O. Y. ATAMAN \\ Department of Chemistry, Bilkent University, 06533 Ankara, Turkey (S. S.); and Department of Chemistry, \\ Middle East Technical University, 06531 Ankara, Turkey (N. E., S. K., O. Y. A)
}

\begin{abstract}
The nature of analyte species collected on a cooled silica tube for atom-trapping atomic absorption spectrometric determin ation was investigated with the use of X-ray photoelctron spectroscopy (XPS). An XPS spectrum of gold deposited on atom-trapping silica tubes reveals a Au $4 f_{7 / 2}$ peak with a binding energy of $84.8( \pm 0.2) \mathrm{eV}$, which falls in the middle of the binding energies corresponding to zerovalent $\mathrm{Au}(0)$ at $84.0 \mathrm{eV}$ and that of monovalent $\mathrm{Au}(\mathrm{I})$ at 85.2 $\mathrm{eV}$. The corresponding energy for $\mathrm{Au}$ vapor deposited on silica is also $84.8 \mathrm{eV}$. Deposition of $\mathrm{AuCl}_{4}^{-}$solution on silica results in two differ ent Au $4 f_{7 / 2}$ peaks with binding energies of 84.8 and $87.3 \mathrm{eV}$ corresponding, respectively, to $A u(0)$ and $A u(I I I)$. Deposition of the same $\mathrm{AuCl}_{4}{ }^{-}$solution on platinum metal again gives two peaks, this time at 84.4 and $87.0 \mathrm{eV}$ energies corresponding again to $\mathrm{Au}(0)$ and $\mathrm{Au}(\mathrm{III})$. Combining all these data, we conclude that gold is trapped on atom-trapping silica surface as zerovalent $\mathrm{Au}(0)$ with a $0.8-\mathrm{eV}$ matrix shift with respect to the metal surface. A similar 0.6-eV shift is also observed between the binding energy of $4 f_{7 / 2} \mathrm{Hg}_{2}{ }^{2+}$ measured in $\mathrm{Hg}_{2}\left(\mathrm{NO}_{3}\right)_{2} \cdot 2 \mathrm{H}_{2} \mathrm{O}$ powder and that deposited on silica.
\end{abstract}

Index Headings: Atom trapping of Au on silica; XPS; Matrix shifts in binding energies.

\section{INTRODUCTION}

Sensitivity of a conventional flame atomic absorption spectrometer (AAS) can be enhanced by using a technique known as atom trapping. ${ }^{1-6}$ In flame atom-trapping AAS, the main idea is in situ preconcentration of analyte atoms. The flame is used as a medium for generating and preconcentrating the atoms before the usual measurement stage. A water-cooled silica tube is mounted in the center and parallel to the burner axis. Upon aspiration of sample solution, analyte atoms condense on the tube for the time required to build up a measurable concentration and are released by shutting off the water and allowing the silica tube to heat up in the flame so that the temperature of the surface of the silica tube rises sufficiently to release the atomic species for detection. In an effort to further increase the sensitivity, the silica tubes were coated by alumina and/or iron oxide. The behavior and optimum conditions for application of the in situ preconcentration technique of atomic absorption spectrometry were investigated for 12 elements with the use of an atom-trapping silica tube and compared with those of conventional AAS. ${ }^{4}$ From the data collected, it was concluded that the technique was more sensitive than conventional flame AAS by one or two orders of magnitude in the characteristic concentration following in situ collection for 2-3 min for most metals and that the relative standard devi-

Received 19 November 1996; accepted 4 March 1997.

* Author to whom correspondence should be sent. ation is only slightly less favorable even at these low levels. ${ }^{4}$

Understanding the mechanism of the collection and atomization at the surface of the silica atom trap has been a key issue not only with respect to the atom-trapping technique but also in connection to atomization by electrothermal techniques. Work by Khalighie et al. suggested that there was a linear relationship between appearance time (defined as the time elapsed between the appearance of the absorption signal and the start of the atomization cycle) and the melting point of the metal under study. ${ }^{3}$ In a recent study, Ellis and Roberts used a multivariate approach in an attempt to improve the model relating appearance times to elemental physical properties such as melting and boiling points and enthalpies of fusion and vaporization. ${ }^{6}$ Their conclusion was that appearance times were related to the melting point and $\Delta H$ of fusion of the element, suggesting that the elements were removed from the tube surface in a liquid form by the scouring action of the flame gases.

The chemical nature of the trapped species has also been a central issue. With the use of the studies based on the relation between the melting points and appearance times, it was suggested that $\mathrm{Au}, \mathrm{Ag}, \mathrm{Cd}, \mathrm{Co}, \mathrm{Cu}, \mathrm{Pb}, \mathrm{Se}$, and $\mathrm{Zn}$ were accumulated as metals, while $\mathrm{K}, \mathrm{Li}, \mathrm{Na}, \mathrm{Cr}$, $\mathrm{Mg}$ and $\mathrm{Mn}$ were trapped as silicates or oxides. In order to improve sensitivity, the collector tube was coated by aspirating $500 \mathrm{mg} / \mathrm{L}$ ammonium metavanadate solution; the yellow stain was investigated by XRD to show the presence of vanadium(III) oxide on the surface. ${ }^{3}$ No surface and/or chemical state-sensitive techniques, however, have been employed for the chemical state of analyte species. In a previous study, we reported an investigation of an alternative atomization technique for atom-trapping AAS. ${ }^{7}$ In this contribution, we report an XPS investigation of the silica surfaces used for atom trapping of $\mathrm{Au}$ after preconcentration step. This, to our knowledge, is the first time that such a direct attempt has been reported.

\section{EXPERIMENTAL}

Silica collector tubes, $6.0 \mathrm{~mm}$ o.d. and $4.0 \mathrm{~mm}$ i.d. (Quartz Scientific Inc., Ohio), were used as trapping surfaces. The $10-\mathrm{cm}$ slot burner of a Perkin-Elmer Model $305 \mathrm{~B}$ atomic absorption spectrometer was used with air and acetylene flow rates regulated by the fuel regulator. Silica tubes were mounted on the flame burner assembly by a holder made from brass, as shown in Fig. 1. Collection (trapping) conditions of $\mathrm{Au}$ from the aspirated standard solution on silica were optimized for obtaining 


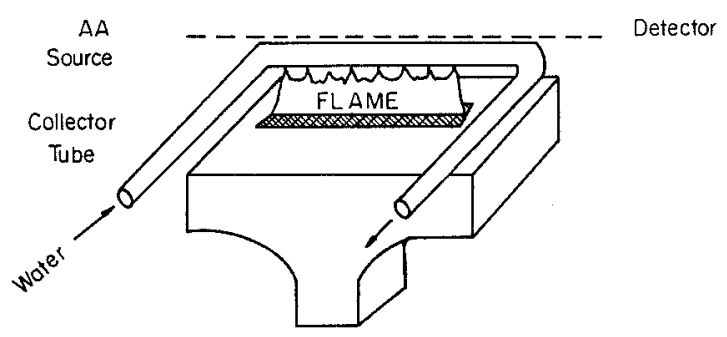

FIG. 1. A schematic diagram of the atom-trapping silica tube used in flame atomic absorption spectrometry.

maximum AAS signal. The height of the silica tube from the burner head was $7.0 \mathrm{~mm}$; flow rates of air and acetylene were $5 \mathrm{~L} / \mathrm{min}$ and $2.8 \mathrm{~L} / \mathrm{min}$, respectively, which corresponded to fuel-lean flame. Forty $\mathrm{mg} / \mathrm{L}$ of $\mathrm{Au}$ solution was aspirated for $10 \mathrm{~min}$ with a $5-\mathrm{mL} / \mathrm{min}$ aspiration rate. The samples were kept in argon atmosphere until surface analysis.

For calibration purposes, besides the use of a gold metal strip, different samples containing 20, 40, and 100 $\AA$ vapor-deposited $\mathrm{Au}$ on silica in vacuum were prepared. For preparing Au calibrants with different oxidation states, several drops of $1000-\mathrm{mg} / \mathrm{L}$ standard $\mathrm{Au}$ solution, which was known to be $\mathrm{AuCl}_{4}{ }^{-}$, were deposited on silica tubes or on metallic gold and platinum strips that were later dried in air. A similar procedure was followed for preparing mercury calibrants. A 1000$\mathrm{mg} / \mathrm{L} \mathrm{Hg}_{2}{ }^{2+}$ standard solution was prepared by dissolving $\mathrm{Hg}_{2}\left(\mathrm{NO}_{3}\right)_{2} \cdot 2 \mathrm{H}_{2} \mathrm{O}$ in water. Several drops of this solution were deposited on silica and dried in air.

XPS measurements were performed on a Kratos ES300 spectrometer with $\mathrm{MgK} \alpha \mathrm{X}$-rays $(1253.6 \mathrm{eV})$. The measured resolution on the $\mathrm{Au} 4 \mathrm{f}_{7 / 2}$ peak of the metallic gold was $1.4 \mathrm{eV}$ [full width at half-maximum (FWHM)]. The base pressure in the spectrometer was kept below $10^{-9}$ mbar during measurement.

\section{RESULTS AND DISCUSSION}

In Fig. 1, a schematic diagram of the atom-trapping silica tube used in this work is shown. Figure 2 displays the XPS spectra of (a) a gold-coated silica tube after the preconcentration step and (b) $\mathrm{AuCl}_{4}{ }^{-}$solution deposited on silica. For the Au trapped on silica, in addition to the $\mathrm{Au} 4 \mathrm{f}$ doublet, the spectra contains additional $\mathrm{C} 1 \mathrm{~s}, \mathrm{O} 1 \mathrm{~s}$, $\mathrm{P} 2 \mathrm{~s}$ and $2 \mathrm{p}$, and $\mathrm{Si} 2 \mathrm{~s}$ and $2 \mathrm{p}$ peaks. Carbon is always present in XPS as a result of hydrocarbon deposits in air and/or vacuum, which is commonly used as an internal energy calibrant at $285.0-\mathrm{eV}$ binding energy. The photoionization cross section of $\mathrm{Au} 4 \mathrm{f}$ is $17 \times$ larger when compared with that of $\mathrm{Si} 2 \mathrm{p}^{8}$ Hence, when the relative intensities are corrected with the sensitivity factors, the atomic $\mathrm{Si} / \mathrm{Au}$ ratio can be determined as approximately 50. Considering the fact that the sampling depth in XPS is only $50 \AA$, the deposited $\mathrm{Au}$ can be estimated to be no more than 1-3 atomic layers. The same holds for $\mathrm{AuCl}_{4}{ }^{-}$ deposited on silica.

The question arises as to the chemical nature of $\mathrm{Au}$ deposited. The measured binding energy of $\mathrm{Au} 4 \mathrm{f}_{7 / 2}$ on atom-trapping silica is $84.8 \mathrm{eV}$ with an estimated uncertainty of $<0.2 \mathrm{eV}$. This value falls in the middle of the tabulated binding energy of 84.0 and 85.2 for the zer-

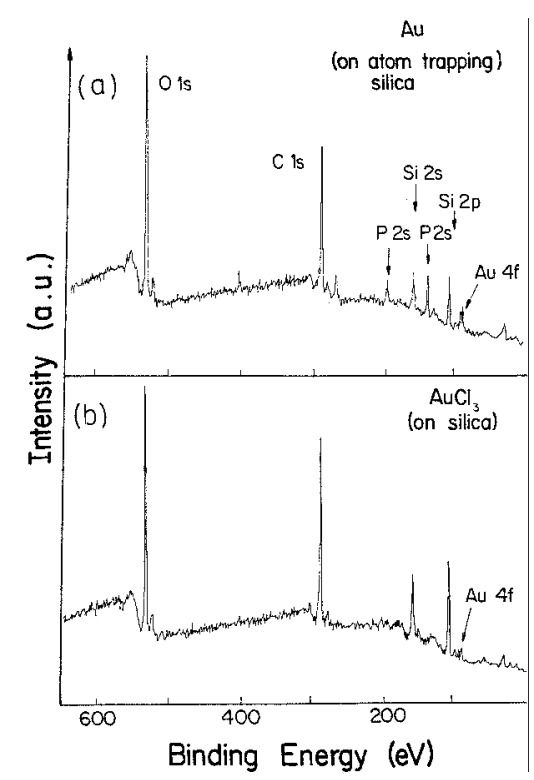

FIG. 2. Part of the XPS spectra (using MgKa (X-rays) of (a) Au deposited on atom-trapping silica from a $40.0-\mathrm{mg} / \mathrm{L} \mathrm{Au}$ solution that was aspirated for $10 \mathrm{~min}$ with a $5-\mathrm{mL} / \mathrm{min}$ aspiration rate, and (b) $\mathrm{AuCl}_{4}$ solution deposited and dried on silica tube.

ovalent $A u(0)$ and monovalent $A u(I)$, respectively; and is farther away from the tabulated binding energy for the trivalent $\mathrm{Au}$ (III), which is $86.7 \mathrm{eV} .{ }^{8}$ However, it is also well known that the binding energies shift, depending on the chemical and/or physical environment. ${ }^{8-10}$ Calibration using only $\mathrm{C} 1 \mathrm{~s}$ levels can be inaccurate, and very careful referencing is needed for more accurate measurements. Gold deposition is, ironically, one of the best methods for referencing other XPS peak energies. ${ }^{8-11}$ The $4 \mathrm{f}_{7 / 2}$ binding energy for the gold metal is $84.0 \mathrm{eV}$, but it is expected that this energy will be shifted on the silica matrix, even if the valency is zero. ${ }^{8}$

To assess the effect of the silica matrix, we prepared Au films with thicknesses varying from 20 to $100 \AA$ by the well-known vacuum deposition technique. The $\mathrm{Au} 4 \mathrm{f}$ binding energy in these films also varies with film thickness, and for the range of $20-40 \AA$ it exactly matches that of $\mathrm{Au}$ on the atom-trapping silica, i.e., $84.8 \mathrm{eV}$. The peaks, however, are broader. The question of the chemical state [whether $\mathrm{Au}(0)$ or $\mathrm{Au}(\mathrm{I})]$ could still not be resolved. We then deposited Au from the 1000-mg/L stock solution containing $\mathrm{AuCl}_{4}{ }^{-}$ions that consisted mainly of $\mathrm{Au}(\mathrm{III})$ in the solution. The presence of $\mathrm{Au}(\mathrm{III})$ in the solution was confirmed from its two UV absorption bands at 324 and $232 \mathrm{~nm} .{ }^{12}$ After drying in air, the thin solid film, which was expected to be $\mathrm{AuCl}_{3}$, was inserted into the spectrometer and its XPS spectrum was recorded. To our surprise, the $\mathrm{Au} 4 \mathrm{f}$ region consisted of four peaks (a doublet of doublets), as shown in Fig. 3. The very same four peaks were also observed when the $\mathrm{AuCl}_{4}{ }^{-}$solution deposition was carried out on $\mathrm{Pt}$ or even $\mathrm{Au}$ foils. These four peaks could be curve-fitted into two 7/2-5/2 doublets with an energy separation of $2.7 \mathrm{eV}$ between them. This $2.7 \mathrm{eV}$ exactly matched the binding energy difference between $\mathrm{Au}(0)$ and $\mathrm{Au}(\mathrm{III})$, indicating that some of $\mathrm{Au}$ (III) on the surface of silica or platinum foil was reduced to the zerovalent metallic state. Furthermore, since Pt 4 f lines were near $(71.2 \mathrm{eV}$ for the $7 / 2$ peak in the 


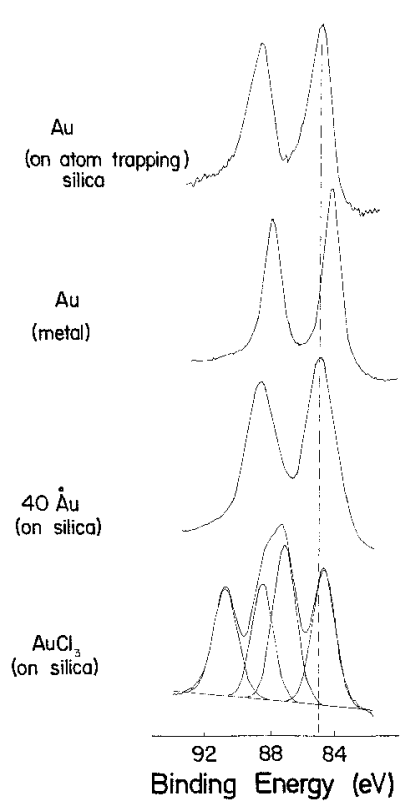

Au $4 f$

Binding Energy (eV)

FIG. 3. $\mathrm{Au} 4 \mathrm{f}_{7 / 2-5 / 2}$ region of the XPS spectra (using MgKa X-rays) of Au deposited on atom trapping silica, Au metal, $40 \AA$ Au vacuum deposited on silica, and $\mathrm{AuCl}_{3}$ deposited on silica from the reference $1000-\mathrm{mg} / \mathrm{L}$ stock solution of $\mathrm{AuCl}_{4}{ }^{-}$after drying.

metal) to the $\mathrm{Au} 4 \mathrm{f}$ lines, very accurate energy calibration could be achieved.

Figure 3 displays the $\mathrm{Au} 4 \mathrm{f}_{7 / 2-5 / 2}$ doublet regions of (1) $\mathrm{Au}$ deposited on atom-trapping silica, (2) the metal, (3) $40 \AA \mathrm{Au}$ vacuum deposited on silica, and (4) $\mathrm{AuCl}_{3}$ deposited on silica from the reference $1000-\mathrm{mg} / \mathrm{L}$ stock solution of $\mathrm{AuCl}_{4}^{-}$after drying. The spectra of $\mathrm{AuCl}_{3}$ deposited on $\mathrm{Pt}$ and $\mathrm{Au}$ metals were also recorded but are not reproduced here. The relevant data are collected in Table I.

The puzzle is solved backwards. $\mathrm{AuCl}_{4}{ }^{-}$deposited on $\mathrm{Pt}$ metal gives two gold species, $\mathrm{Au}(0)$ and $\mathrm{Au}(\mathrm{III})$, with the corresponding $4 \mathrm{f}_{7 / 2}$ binding energies at 84.4 and 87.3eV, respectively. The same $\mathrm{AuCl}_{4}{ }^{-}$deposited on silica also yields the same two gold species, the binding energies of which are now $0.8 \mathrm{eV}$ higher than the corresponding ones on the Au metal. Hence, the 84.8-eV Au $4 \mathrm{f}_{7 / 2}$ peak observed for the atom-trapping silica can now clearly be assigned to metallic zerovalent $\mathrm{Au}(0)$. The 0.8 $\mathrm{eV}$ difference between the binding energies on metals and on silica is attributed solely to the matrix effect.

To verify this matrix shift, we carried out similar measurements on $\mathrm{Hg} 4 \mathrm{f}$ levels. $\mathrm{Hg}$ is next to $\mathrm{Au}$ in the periodic table, with a similar $4 \mathrm{f}$ binding energy and cross section, and is also known to have variable valency. Due to the very high vapor pressure of the elemental mercury, measurements were carried out on a compound of $\mathrm{Hg}$ in powder form and after deposition on silica. The measured $\mathrm{Hg} 4 \mathrm{f}_{7 / 2}$ binding energy of $\mathrm{Hg}_{2}{ }^{2+}$ on silica is $102.0 \mathrm{eV}$ and is $0.6 \mathrm{eV}$ larger than that of $\mathrm{Hg}_{2}{ }^{2+}$ measured in powders of $\mathrm{Hg}_{2}\left(\mathrm{NO}_{3}\right)_{2} \cdot 2 \mathrm{H}_{2} \mathrm{O}$ as given in Table I. The matrix shift on $\mathrm{Hg} 4 \mathrm{f}$ is not only in the right direction and but is also comparable in magnitude to the one on $\mathrm{Au} 4 \mathrm{f}$.

The mechanism(s) of atomization into the flame, de-
TABLE I. Measured binding energies (in eV) and FWHM (shown in parentheses and in $\mathrm{eV}$ ) of the various $\mathrm{Au}$ and $\mathrm{Hg} \mathbf{4 f}_{7 / 12}$ peaks using $\operatorname{MgK} \alpha \mathrm{X}$-rays.

\begin{tabular}{lccc}
\hline & $\mathrm{Au}(0)$ & $\mathrm{Au}(\mathrm{I})$ & $\mathrm{Au}(\mathrm{III})$ \\
\hline $\mathrm{Au}$ (deposited on atom-trapping & & & \\
$\quad$ silica) & $84.8(1.6)$ & & \\
$\mathrm{Au}$ (metal) & $84.0(1.4)$ & & \\
$40 \mathrm{~A} \mathrm{Au}$ (vacuum deposited on & & & \\
$\quad$ silica) & $84.8(2.2)$ & & \\
$\mathrm{AuCl}_{3}$ (deposited on silica) & $84.7(1.8)$ & $\ldots$ & $87.4(1.9)$ \\
$\mathrm{AuCl}_{3}$ (deposited on Pt) & $84.4(1.9)$ & $\ldots$ & $87.1(2.0)$ \\
& $\underline{\mathrm{Hg}(0)}$ & $\underline{\mathrm{Hg}(\mathrm{I})}$ & \\
$\mathrm{Hg}($ metal) & $99.9^{\mathrm{a}}$ & $\ldots$ & \\
$\mathrm{Hg}_{2}\left(\mathrm{NO}_{3}\right)_{2}$ & $\ldots$ & $101.2 \mathrm{a}$ & \\
$\mathrm{Hg}_{2}\left(\mathrm{NO}_{3}\right)_{2} \cdot 2 \mathrm{H}_{2} \mathrm{O}$ (powder) & $\ldots$ & $101.4(2.0)$ & \\
$\mathrm{Hg}_{2}\left(\mathrm{NO}_{3}\right)_{2} \cdot 2 \mathrm{H}_{2} \mathrm{O}$ (deposited & & & \\
on silica) & $\ldots$ & $102.0(2.0)$ & \\
\hline
\end{tabular}

${ }^{a}$ From Ref. 8.

position onto the (water-cooled) silica surfaces during preconcentration, and later atomization from the surface of the reheated silica back into the flame are relatively complex and are believed to involve active participation of both flame constituents and silica surfaces. The roles played by each process, we believe, are different for each element. Elucidating the roles of all or part of the constituents will not only aid in understanding the mechanism(s) but will also help improve the sensitivity of the relatively simple, widely used, and almost interferencefree analytical tool, flame atomic absorption spectrometry. In this work, our contribution has been the determination of the chemical state of the trapped $\mathrm{Au}$ on silica, and we are presently carrying out similar measurements on other elements.

\section{ACK NOWLEDGMENTS}

This work is supported by TÜBITAK, the Scientific and Technical Research Council of Turkey, through the Grants TBAG-COST/1 and TBAG-1230, as well as the Grant AFP-95-01-03-03 from the Middle East Technical University Research Fund.

1. C. Lau, A. Held, and R. Stephens, Can. J. Spectrosc. 21, 100 (1976).

2. J. Khalighie, A. M. Ure, and T. S. West, Anal. Chim. Acta 107, 191 (1979).

3. J. Khalighie, A. M. Ure, and T. S. West, Anal. Chim. Acta 117, 257 (1980).

4. T. West, Anal. Proc. 25, 240 (1988).

5. S. H. Wen, Y. Li-Li, and Z. D. Ciang, J. Anal. At. Spectrom. 11, 265 (1996).

6. L. A. Ellis and D. J. Roberts, J. Anal. At. Spectrom. 11, 259 (1996).

7. O. Y. Ataman, N. Ertaş, R. S. Helles, and S. Kumser, "Alternative Atomization Techniques in Atom Trapping AAS", FACSS XX Annual Conference, Detroit, Michigan (1993).

8. D. Briggs and M. P. Seah, Practical Surface Analysis (Wiley, Chichester, 1996), 2nd ed.

9. C. Battistoni, G. Mattogno, L. Naldini, and R. Zanoni, J. Electron. Spectrosc. Relat. Phenom. 28, 23 (1982).

10. C. Battistoni, G. Mattogno, and D. M. P. Mingos, J. Electron. Spectrosc. Relat. Phenom. 33, 107 (1984).

11. Y. Uwamino, T. Ishizuka, and H. Yamatera, J. Electron. Spectrosc. Relat. Phenom. 28, 23 (1980).

12. W. R. Mason and H. B. Gray, Inorg. Chem.7, 55 (1968). 